\title{
Conexões
}

\section{Promoção da saúde no contexto do SUS: análise das práticas cotidianas à luz da clínica ampliada \\ em um grupo de promoção da saúde de uma UBS capixaba}

\author{
Moises da Silva Roberto ${ }^{1}$ \\ Marcos Bagrichevsky ${ }^{2}$
}

\section{RESUMO}

Este artigo analisa, à luz da Clínica Ampliada, as práticas de promoção da saúde ofertadas em um Grupo de Promoção da Saúde (GPS) denominado Grupo de Homens (GH) desenvolvido em uma UBS capixaba, buscando identificar os avanços e desafios, e compreender o contexto de produção das práticas e da participação dos usuários. Trata-se de pesquisa qualitativa que agregou registros etnográficos como forma de apreender os fenômenos ocorrentes no grupo. Os "dados" permitiram a identificação de três categorias: a) espaço comunicacional: analisa o GH na ótica da escuta dos sujeitos, buscando identificar se eles têm abertura para a fala e escuta além da conversa "mecânica" focada em patologias específicas; b) desenvolvimento de vínculo: analisa o relacionamento entre os sujeitos (usuários e equipe de saúde), com intuito de verificar se o relacionamento é próximo ou se é formal e burocrático, apontando as vantagens do vínculo para o cuidado em saúde e os desafios para sua concretização no $\mathrm{GH} ; \mathrm{c}$ ) protagonismo: analisa o comportamento e a participação dos usuários no $\mathrm{GH}$, identificando se eles são considerados e se agem como "sujeitos" detentores de autonomia ou se são vistos e agem como meros "pacientes". Finalmente, aponta os desafios para desenvolver o protagonismo deles.

Palavras Chave: Saúde do homem. Promoção da saúde. Integralidade. Clínica ampliada.

\footnotetext{
${ }^{1}$ Universidade Federal de Santa Catarina

${ }^{2}$ Universidade Estadual de Campinas

Submetido em: 21 nov. 2017

Aceito em: 22 jan. 2018

Contato: moisesdasilvaroberto@hotmail.com
} 


\section{A BSTRACT}

This article analyzes, in light of the Expanded Clinic, how health promotion practices of a Health Promotion Group Called Group of Men developed in a UBS capixaba, seeking to identify the advances and challenges, and understand the context of production practices and user participation. It is a qualitative research that added ethnographic records as a way of apprehending the phenomena occurring in the group. The data allowed the identification of three categories: a) communication space: analyzes the GH from the perspective of listening to the subjects, seeking to identify if they have openness to speech and listening beyond the "mechanical" conversation focused on specific pathologies; b) development of bond: analyzes the relationship between the subjects (users and health team), in order to verify if the relationship is close or if it is formal and bureaucratic, pointing out the advantages of the link to health care and the challenges to its implementation in $\mathrm{GH}$; c) leadership: analyzes the behavior and participation of users in $\mathrm{GH}$, identifying whether they are considered and acting as "subjects" holding autonomy or if they are seen and act as mere patients. Finally, it points out the challenges to develop their protagonism.

Keywords: Health man. Health promotion. Integrality. Expanded clinic.

\section{RESUMEN}

Este artículo analiza, a la luz de la Clínica Ampliada, las prácticas de promoción de la salud ofrecidas en un Grupo de Promoción de la Salud denominado Grupo de Hombres desarrollado en una UBS capixaba, buscando identificar los avances y desafíos, y comprender el contexto de producción de las prácticas y la participación de los usuarios. Se trata de una investigación cualitativa que ha agregado registros etnográficos como forma de aprehender los fenómenos ocurrentes en el grupo. Los "datos" permitieron la identificación de tres categorías: a) espacio comunicacional: analiza el GH en la óptica de la escucha de los sujetos, buscando identificar si ellos tienen apertura para el habla y escucha más allá de la conversación "mecánica" enfocada en patologías específicas; b) desarrollo de vínculo: analiza la relación entre los sujetos (usuarios y equipo de salud), con el fin de verificar si la relación es cercana o si es formal y burocrático, apuntando las ventajas del vínculo para el cuidado en salud y los desafíos para su concreción en el GH; c) protagonismo: analiza el comportamiento y la participación de los usuarios en el GH, identificando si son considerados y se actúan como "sujetos" poseedores de autonomía o si se ven y actúan como meros "pacientes". Finalmente, apunta los desafíos para desarrollar su protagonismo.

Palabras Clave: Salud del hombre. Promoción de la salud. Integrida. Clínica ampliada 


\section{CONSIDERAÇÕES INICIAIS}

A promoção da saúde (PS) articula-se com a diversidade de práticas desenvolvidas nos serviços de saúde. É elemento estratégico na busca de práticas de cuidado mais promissoras, colaborando para a consolidação do Sistema Único de Saúde (SUS) enquanto Política Pública. Entretanto, a PS tem sido descrita de várias maneiras na literatura científica. Sua polissemia acompanha e influencia as diversas práticas de saúde que recebem o mesmo nome (IGLESIAS; DALBELLO-ARAUJO, 2011; VASCONCELOS; SCHMALLER, 2014). É neste sentido que Iglesias e DalbelloAraujo (2011) ressaltaram a importância de realização de estudos que analisem como tais concepções (sobre saúde e sua promoção) têm se atualizado na prática profissional.

A Unidade Básica de Saúde (UBS) Azul (nome fictício), localizada em um município capixaba, é um cenário privilegiado para investigação em relação ao tema PS, pois possui projetos educativos desenvolvidos por equipes da Estratégia Saúde da Família (ESF), por intermédio de Grupos de Promoção da Saúde (GPS). A escolha desse campo de pesquisa levou em conta que a ESF se organiza tendo a promoção da saúde como um dos eixos fundamentais como direcionalidade política e técnica na ruptura com o modelo curativo e hospitalocêntrico de atenção à saúde.

Partindo da compreensão do processo saúde-doença como fenômeno sociocultural, o propósito desta pesquisa foi realizar um estudo descritivo-analítico qualitativo acerca das práticas cotidianas à luz da perspectiva da Clínica Ampliada no GPS denominado de Grupo de Homens (GH) desenvolvido na UBS Azul. Os objetivos específicos incluem descrever, analisar, compreender e problematizar as práticas de PS e suas implicações no cuidado em saúde, buscando identificar os avanços e desafios, e compreender o contexto de produção das práticas. Ressalta-se que este artigo se trata de um recorte de uma dissertação de mestrado apresentada em 2016 ao Programa de PósGraduação em EF da Universidade Federal do Espírito Santo (UFES).

$\mathrm{O}$ GH atende homens residentes nos territórios adstritos à UBS Azul. A maior parte destes territórios se localiza em morros adjacentes, em região empobrecida da cidade, com áreas de risco social devido a moradias precárias e existência de regiões onde ocorre intenso narcotráfico. O GH promove a saúde com base em três estratégias que são desenvolvidas por uma equipe interdisciplinar: oficinas terapêuticas, educação em saúde e atividades lúdicas. O maior objetivo operacional da oficina terapêutica é o fomento da expressão dos participantes (SOUZA, et al., 2015), buscando abertura para a fala e para a escuta dos sujeitos. Por meio da educação em saúde, os profissionais fazem exposições dialogadas acerca de temas variados, que possuem relação com o contexto de vida dos sujeitos. As atividades lúdicas abarcam os diferentes interesses culturais do 
lazer ${ }^{1}$ que por vezes se entrelaçam: interesses artísticos, intelectuais, físicos; manuais, turístico e sociais.

\section{Percurso Metodológico}

Os caminhos investigativos transitaram pelos pressupostos da pesquisa qualitativa, tomando as atividades cotidianas do $\mathrm{GH}$ como perspectiva metodológica e agregando registros etnográficos (caderneta, fotos e filmagens) como forma de apreender os fenômenos ocorrentes no grupo. No total, foram 30 sessões, aleatórias, de observação participante no GH durante o mestrado em Educação Física, turma 2014. Os encontros do GH têm início previsto para as $08 \mathrm{hs}$, sendo que o auditório da UBS é o ponto de encontro entre profissionais, acadêmicos e usuários. As atividades coletivas duram cerca de 90 minutos e contam com 10 usuários em média. Após as atividades coletivas, habitualmente os profissionais e acadêmicos se reúnem a fim de discutirem sobre a dinâmica do grupo

A análise empírica se deu a partir de informações sistematizadas no diário de campo. Foi realizada leitura "flutuante" dele, fazendo em seguida a análise categorial das temáticas, baseado na Análise Temática de Conteúdo (CAMPOS C. J. G., 2004; CÂMARA, 2013; CAVALCANTE; CALIXTO; PINHEIRO, 2014). Foi utilizada a categorização "não apriorística", cujo processo se deu por "frequenciamento" (repetição de conteúdos) e por "relevância implícita" (conteúdo relevante para o estudo apesar de não se repetir) (CAMPOS C. J. G., 2004). Ressalta-se que os nomes das pessoas e da UBS aqui registrados são fictícios, preservando suas identidades originais, e algumas de suas falas foram corrigidas gramaticalmente para otimizar o entendimento.

\section{Análise e Discussão}

A análise levou à formulação de três categorias acerca das práticas de PS desenvolvidas no GH: a) espaço comunicacional: analisa o GH na ótica da escuta, diálogo e expressão dos participantes do GH, buscando identificar se os sujeitos têm abertura para a fala e escuta além da conversa "mecânica" focada em patologias específicas (anamnese tradicional); b) desenvolvimento de vínculo: examina o espaço do GH no que tange ao relacionamento entre os sujeitos (usuários e equipe de saúde), verificando se o relacionamento é próximo ou se é formal e burocrático, apontando as vantagens da formação do vínculo para o cuidado em saúde e os desafios para sua concretização no $\mathrm{GH}$; c) protagonismo: analisa o comportamento e a participação dos usuários, identificando se eles são considerados e se agem como "sujeitos" detentores de autonomia ou se são vistos e agem como meros "pacientes". Por fim, aponta os desafios para desenvolver o protagonismo deles.

\footnotetext{
${ }^{1}$ Par mais informações acerca dos interesses culturais do lazer, ver Dumazedier, Jofre, Valores e conteúdos culturais do lazer. São Paulo: SESC, 1980. 176p.

Conexões: Educ. Fís., Esporte e Saúde, Campinas: SP, v. 16, n. 1, p. 49-69, jan./mar. 2018. ISSN: 1980-9030
} 
Esta análise traz a possibilidade de verificar como estas categorias constroem uma relação que permite uma avaliação mais clara em termos de práticas de saúde desenvolvidas no GH, e quais são os avanços e os desafios. Cada categoria se articula às dimensões: a) conceitual: constitui aspectos teóricos acerca dos temas analisados pelas categorias; b) programática: aborda como a equipe de saúde se organiza a fim de desenvolver as práticas que abrangem aspectos contidos na dimensão conceitual; e c) relacional: trata de como os sujeitos interagem entre si para alcançarem os objetivos, no caso, comunicação, vínculo e protagonismo dos usuários.

\section{Espaço Comunicacional}

A análise evidenciou que a equipe de saúde utiliza o conceito da Clínica Ampliada, proposta que leva em conta a dialética entre os sujeitos na complexidade de suas dimensões biopsicossociais. Esse conceito pressupõe a postura de acolhimento às falas das pessoas, elaboração de atividades não só relacionadas a doenças, mas a atenção aos afetos e vínculos construídos entre os atores do cuidado. Esta estratégia propõe "pensar junto" sobre os problemas, fomentando o vínculo e a corresponsabilização no cuidado em saúde (SOUZA, 2012; SOUZA et al., 2015). Com esta perspectiva de atuação, foi constatado estímulo para os sujeitos discutirem temas variados, mesmo "delicados", que evidenciam, por exemplo, relações com a violência e com a sexualidade.

Questões sobre violência emergiam com frequência nas falas dos participantes do grupo.

"[...] meu filho só me dá desgosto. Passa mais tempo preso do que solto [com expressão de tristeza e com olhos lacrimejando]" (Cafú, $1^{\text {a }}$ sessão de observação).

“[...] quando a polícia estava chegando, meu colega me deu a arma para eu esconder. [...] meu colega tem arma, pois é do 'movimento' [tráfico de drogas]" (Kaká, 7 ${ }^{a}$ sessão de observação).

"Mataram um adolescente ali na esquina. Era de tarde ainda. Eu estava perto na hora. Conheço a mãe do rapaz. Ela também estava na hora. Me sinto aterrorizado! [...] menor mata e não tem punição." (Zizinho, 30 a sessão de observação).

"Sou alvo dessa violência, tenho dois filhos envolvidos com a criminalidade. Meu filho mais velho foi morto com trinta tiros em casa, se eu estivesse em casa morreria também, porque não ia deixar eles matarem meu filho" (Cafú, 30ª sessão de observação).

Não obstante à tendência para certa abertura no GH, os conflitos e alguns fatos, expostos pelos usuários, foram censurados:

"O papo não colocou, mas pai e mãe têm que educar para o filho não fazer besteira!" (Garrincha, 30ª sessão de observação). 
Imediatamente, o enfermeiro Bonifácio argumentou:

"Não podemos esquecer que são várias as instituições responsáveis pela formação da pessoa, sendo a família apenas uma delas. O caso de [Cafú] é um exemplo: ele perdeu um filho e o outro está preso devido à criminalidade. Por isso é injusto culparmos os pais, pois há outros fatores envolvidos" (enfermeiro Bonifácio, $30^{\mathrm{a}}$ sessão de observação).

Naquele momento já havia participantes em pé para irem embora e essas falas encerraram aquele encontro, sem dar continuidade à ideia do participante Garrincha. $\mathrm{O}$ que se percebe é a necessidade de ampliação dos "não ditos" no grupo rumo à escutaexperimentação abordada por Heckert (2007).

A sexualidade foi outro tema que emergiu durante a pesquisa de campo. Trata-se de mais um tema difícil de ser discutido, pelo menos sem a constituição de um espaço protegido para a fala e a escuta (BRASIL, 2009). No GH, a acadêmica Simone conduziu uma oficina terapêutica composta por dezessete frases relacionadas ao tema sexualidade. Ela distribuiu para cada participante, profissional e acadêmico uma frase (escrita em um pedaço de papel) sobre esse tema. Cada pessoa leu sua frase para o grupo e todos foram estimulados a opinarem ou fazerem questionamento sobre o assunto (Diário de campo, $9^{\mathrm{a}}$ sessão de observação).

"Não precisa fazer sexo todo dia. Quando eu era mais jovem eu achava que tinha que transar todos os dias. Mas agora sei que não é assim. Quando eu era adolescente cheguei a ter 14 namoradas. Mas hoje tenho uma mulher que vale por 10 mulheres. [...] Se a esposa chega cansada do trabalho em casa, o marido não deve acordá-la para transar. É melhor o marido deixar para outra hora" (Sócrates, $9^{a}$ sessão de observação).

"Isso [a redução da potência sexual depois dos 40 anos] depende do estilo de vida que a pessoa leva. Sua alimentação, estado psicológico, o trabalho" (Falcão, $9^{a}$ sessão de observação).

Antes do início daquela oficina terapêutica havia cinco mulheres (duas profissionais e três acadêmicas) no auditório da UBS, além de Simone, mas a psicóloga Amália se ausentou antes mesmo do início da oficina terapêutica. Os participantes do GH demonstraram não se importarem em falar de sexualidade na presença da profissional e acadêmdicas (Diário de campo, $9^{a}$ sessão de observação). No entanto, a ideia de uma mulher abordar o tema sexualidade para um grupo de homens causou certo incômodo, conforme relato da acadêmica Simone no encontro seguinte:

“[...] Tinha uma profissional que ficou receosa de eu [elevando as mãos em direção aos peitorais], como mulher, conduzir uma atividade que falasse de sexualidade com o grupo. Eu falei: deixa comigo! [risos] Aí, antes de eu começar, ela saiu discretamente da sala, preocupada. Me falou que não queria nem ver! Voltou só depois. E 
deu certo [risos]! Eles [frequentadores do $\mathrm{GH}$ ] participaram muito. [...] Por isso pensei em fazer uma dinâmica com os profissionais também! [...]" (Simone na reunião de equipe, $10^{\mathrm{a}}$ sessão de observação).

Nota-se que o grupo precisa se tornar um espaço protegido que possibilite cada pessoa ser espontânea, pensar sem restrições, sem receio, sem timidez, ou com vergonha e com medo, mas com acolhimento e permissão para esses sentimentos (FURLAN; CAMPOS, 2010). Ao propiciar os usuários se sentirem "seguros", aumenta-se a chance de eles compartilharem relatos que, sem a constituição de um espaço aberto para o diálogo, são "censurados".

"[...] Eu fiz este exame de toque [retal] pela primeira vez só agora, com 67 anos de idade [...]" (Jacozinho, $7^{\mathrm{a}}$ sessão de observação).

Uma fala dessa teria pouca chance preventiva, questão aludida por diversos estudos (BRASIL, 2008; SEPARAVICH de emergir em um espaço coletivo sem integração grupal e onde impera o modelo hegemônico de masculinidade. Ela também denota a exígua presença de homens nos serviços de saúde numa perspectiva; CANESQUI, 2013). Assim, as estratégias que buscam abordar temáticas sobre saúde do homem auxiliam na desmistificação da crença de que se deve evitar falar de sexualidade, doenças sexuais, entre outras questões.

"[...] Os homens até vêm para consultas [na UBS], com perguntas prontas sobre estes assuntos [sobre intimidade e sexualidade]. Mas, quando o paciente entra no consultório e ver uma médica em vez de médico, ele corta estes assuntos da conversa com a médica" (Sócrates, $7^{\mathrm{a}}$ sessão de observação).

"Eu sou assim [tímido]. Não falo toda verdade para o médico não" (Kaká, 14ª sessão de observação).

Considerando o cenário de afastamento dos homens da ABS, muitos deles nem possuem cartão da UBS. A estratégia de grupo voltado ao público masculino, como o $\mathrm{GH}$, tem potencial de reverter esse quadro. Para isso, é preciso que os serviços possuam abertura para acolher este publico, favorecendo a ressignificação das vivências masculinas frente ao modelo imperativo de masculinidade contemporâneo, bem como a capacidade de lidar com assuntos mais frequentes entre os homens.

Observa-se que a conformação do GH em um espaço comunicacional o aproxima da dimensão conceitual da escuta qualificada, pois se percebe que a escuta empreendida no GH não está interessada apenas em sintomas de certas enfermidades, mas abarca relações dos sujeitos com outras questões da vida. Nota-se que a equipe interdisciplinar de saúde realizou, dentro das limitações, o acolhimento dos sujeitos, tanto que os profissionais e acadêmicos apostaram em práticas que favoreceram a expressão dos usuários dos serviços. Nesse sentido, constata-se que o acolhimento no GH foi além da mera "recepção" ou "triagem" do usuário na UBS. No que tange a dimensão relacional, 
nota-se que os sujeitos demonstram ter no GH um canal facilitado para exercerem a comunicação de forma menos formal em relação às consultas individuais tradicionais, expondo elementos essenciais de suas vidas para o cuidado em saúde. Em relação à dimensão programática, salienta-se a tendência por parte de alguns da equipe de saúde de apartar profissionais e determinados temas em virtude da concepção de gênero, como ocorreu no episódio da psicóloga Amália que discordou de uma acadêmica conduzir uma discussão com o tema sexualidade no GH. Frisa-se também a propensão de "evitar" certos assuntos levantados pelos usuários dos serviços, temas que fazem parte de suas vidas, a exemplo da questão colocada por Garrincha em relação à responsabilidade dos pais na educação e criação dos filhos, mas que o enfermeiro Bonifácio não deu sequência. Neste aspecto, é importante fazer cada membro da equipe de saúde ter clareza acerca da Clínica Ampliada e suas abordagens, principalmente as "atitudes psicoterapêuticas" nos termos de Souza (2012) e Souza et al. (2015). E isso pode ser viabilizado por intermédio do incentivo e inclusão destas abordagens no currículo dos cursos de graduação e pós-graduação do campo da saúde, nos cursos de formação continuada e pelo incentivo do trabalho/estágio em equipe interdisciplinar e fortalecimento de parcerias entre serviços de saúde e universidades, parcerias que no GH evidenciaram suas potencialidades para enriquecer as práticas de saúde numa dupla direção, beneficiando a academia e os usuários dos serviços.

\section{Desenvolvimento do Vínculo}

Outro aspecto do $\mathrm{GH}$, emergente a partir da análise do diário de campo, é o desenvolvimento do vínculo dos participantes com a equipe de saúde e entre si. Os "dados" apontam que as atividades lúdicas e as práticas esportivas o favoreceram.

Durante a $8^{\mathrm{a}}$ e $13^{\mathrm{a}}$ sessões de observação, os participantes do GH e equipe de saúde jogaram futebol na quadra de uma ONG local. Foi notória a expressão de prazer proporcionada por essa atividade que tem potencial de integrar os sujeitos, bem como de contribuir, ao constituir como "nova" fonte de satisfação, para que se opere a substituição da recompensa percebida ao se consumir substâncias químicas, considerando que no GH há participantes com comportamento de risco em relação ao uso de álcool e/ou drogas (AD).

No decorrer das partidas de futebol no GH, foi notado o cuidado entre as pessoas das equipes a fim de evitarem possíveis lesões devido o contato físico. Segundo alguns profissionais, nos primeiros jogos havia muito "quebra-quebra", ou seja, com o tempo os participantes mudaram a dinâmica de jogo. Eles passaram a perceber que ao evitarem jogadas mais "duras", estariam protegendo a si mesmos e aos outros, o que ratifica a ideia de cooperação em atividades coletivas. 
Outra evidência do desenvolvimento de vínculo é a assiduidade dos participantes. Mesmo em dias chuvosos, foi notado que os participantes compareceram, embora em menor número. Em uma manhã chuvosa, foi observado que ela estava com menos usuários que habitualmente ficam nas filas para marcação de consultas. Naquela manhã, cinco participantes se reuniram no auditório da UBS (Zizinho, Kaká, Sócrates, Raí e Dunga), apesar de ter chovido bastante (Diário de campo, $11^{\mathrm{a}}$ sessão de observação). Fato semelhante ocorreu no encontro seguinte:

"Até agora só tem dois participantes [Sócrates e Tostão]. Acho que não vai vir muita gente hoje por causa da chuva" (enfermeiro Bonifácio em uma conversa com o mestrando num corredor da UBS antes das atividades coletivas, $12^{\mathrm{a}}$ sessão de observação).

Apesar da intensa chuva, em cerca de 30 minutos outros participantes foram chegando: Zizinho, Bebeto, Kaká, Raí, Cafú, Ronaldinho, Dinamite, Pato, Neymar e Ramires, totalizando 12 participantes presentes, surpreendendo a equipe de saúde (Diário de campo, 12ª sessão de observação).

Há participantes do GH que o aderiram de tal forma que mesmo nos dias em que não foi possível estarem presentes durante todo o encontro, compareceram, ainda que por alguns minutos. O participante Sócrates compareceu no auditório em uma manhã, mesmo sabendo que não daria para participar das atividades do $\mathrm{GH}$, pois ele iria montar móveis em uma loja no horário do encontro do GH, (ele é aposentado e faz "freelance") - dia em que sofreu infarto, enquanto trabalhava na loja. Contudo, Sócrates foi até o auditório da UBS onde ficou sentado por alguns minutos, conversando com os demais participantes do $\mathrm{GH}$, e onde teve a PA e glicemia aferidas - que estavam normais (Diário de campo, 13 ${ }^{\text {a }}$ sessão de observação). Semelhantemente, o senhor Zizinho compareceu no auditório em uma manhã, mesmo sabendo que não permaneceria no encontro, pois ele tinha consulta médica agendada para aquela manhã na UBS (Diário de campo, $17^{\text {a }}$ sessão de observação). Nessa direção, Jairzinho foi ao auditório mesmo quando o encontro estava praticamente se encerrando, em uma manhã, após sair de uma consulta na unidade de saúde (Diário de campo, 26 $6^{\mathrm{a}}$ sessão de observação). Da mesma forma, destaca-se um acontecimento com Kaká que chegou atrasado no dia em que o grupo tinha agendada uma visita ao Planetário localizado na UFES. Então, ele foi sozinho para lá. Mas a sessão já havia começado quando Kaká chegou ao Planetário. Apesar disso, Kaká não foi embora, permanecendo sentado esperando o grupo sair da sessão (Diário de campo, $25^{\mathrm{a}}$ sessão de observação). Esses relatos evidenciam o vínculo dos participantes com o grupo, importante elemento para a promoção da saúde dos sujeitos, pois o vínculo possibilita a compreensão acerca do outro com sua história, o modo como ele se relaciona com as pessoas e como interage com os objetos no mundo (FURLAN; CAMPOS, 2010).

Por outro lado, nota-se que os profissionais da UBS agendaram consultas para participantes do GH no horário desse grupo que se reúne apenas uma vez por semana. Tais fatos põem em evidência a necessidade de as equipes de saúde da UBS Azul se Conexões: Educ. Fís., Esporte e Saúde, Campinas: SP, v. 16, n. 1, p. 49-69, jan./mar. 2018. ISSN: 1980-9030 
articularem e se comunicarem melhor, convergindo, assim, com a perspectiva de trabalho em equipe interdisciplinar (indo além do multiprofissionalismo), a fim de não haver conflitos de horários entre consultas médicas e práticas grupais de PS que têm alcances distintos, consoante Ferreira Neto e Kind (2011).

Outra barreira ao acesso aos serviços e, por conseguinte, ao vínculo, está relacionada à dimensão programática. Após o encerramento de um encontro, o mestrando solicitou ao enfermeiro Bonifácio atender o participante Vavá, visto que sua taxa glicêmica continuava alta desde o encontro da semana anterior, dia em que foi constatado $370 \mathrm{mg} / \mathrm{dL}$ de glicemia. Todavia, Bonifácio apenas informou Vavá acerca do período de marcação de consulta médica da UBS e sugeriu a esse participante verificar detalhes da agenda médica na recepção (Diário de campo, 19 ${ }^{\mathrm{a}}$ sessão de observação). Nessa mesma direção, destaca-se o diálogo abaixo ocorrido no dia que o dentista da UBS, Dr. Amoroso, foi convidado para proferir uma palestra no GH:

"Falando em dente, estou precisando fazer revisão" (Kaká, 15ª sessão de observação).

"Na próxima terça feira teremos aqui cedo o agendamento para o consultório dentário. Aí vocês vêm para marcar" (Dr. Amoroso, 15 a sessão de observação).

Ao considerar o contexto de exígua presença masculina nos serviços de saúde numa perspectiva preventiva (BRASIL, 2008; SEPARAVICH; CANESQUI, 2013), a equipe de saúde desperdiçou oportunidades para acolher esses usuários e suas demandas explícitas de saúde, ignorando também demandas implícitas que só o acolhimento e a escuta qualificada permitiriam identificar. Embora os usuários estivessem de frente com os profissionais da UBS, para eles conseguirem atendimento seria necessário irem para a tradicional fila, cujo número de vagas é limitado e elas são, comumente, preenchidas por ordem de chegada, evidenciando uma mistura de lógica de consultório médico privado dentro de/e sinérgica com o serviço público de saúde (TESSER; POLI NETO; CAMPOS, 2010). Essa realidade diverge da proposta do acolhimento, que objetiva reduzir a fragmentação dos atendimentos prestados pelas diversas áreas, bem como resolver o problema da demanda que em muitos casos é reprimida e evitar as "listas de espera". Para tanto, o acolhimento aqui defendido busca substituir a triagem pela ação, com intuito de atender a todos de acordo com as necessidades específicas de cada sujeito (HENNINGTON, 2005).

Sublinha-se outra questão organizacional que se opõe ao vínculo no $\mathrm{GH}$. Seu desenvolvido no GH também desvela uma face dura, considerando que os participantes sentem a ausência de profissionais que deixaram o grupo, que mudaram de setor e de acadêmicos que passaram pelo grupo durante a realização de estágio supervisionado ou Programa de Educação pelo Trabalho para a Saúde (PET-Saúde).

"Senti falta de muita gente aqui. Igual aquela menina boa que tinha aqui, esqueci o nome dela, a psicóloga [se referindo à psicóloga 
Amícia que trabalhava na UBS]. Não estou vendo mais aqui a [Amália] [atual psicóloga da UBS]. Tem também os estagiários que passam pelo grupo e somem!" (Cafú, 12 $2^{a}$ sessão de observação).

A rotatividade de acadêmicos é até explicável, uma vez que eles passam pela UBS durante o período do curso. Porém, aqui vale salientar que a rotatividade em demasia de profissionais aponta para a indefinição da política de pessoal (valorização e formação de trabalhadores) do SUS, inclusive com existência de contratos temporários, repercutindo na remuneração e na carreira dos profissionais. Diante deste cenário, o SUS enfrenta desafios quanto ao desenvolvimento de vínculo com os usuários e equipe de trabalhadores. Essa questão é debatida por Gadelha (2008) e Campos G. W. S (2008, 2015), que frisam a incapacidade de os municípios instituírem sozinhos uma política de pessoal efetiva e que garanta boa qualidade e estabilidade ao SUS. Para esses autores é essencial maior participação da União e dos Estados no financiamento e na gestão do SUS a fim de qualificar o trabalho em saúde e reverter essa situação.

Não obstante, é inegável a existência de indícios de vínculo no grupo, elemento que suscita possibilidades para que seja consolidada uma relação de segurança, confiança e companheirismo entre os atores do grupo, oportunizando práticas mais ricas e participativas. Foi observado, além da cooperação no futebol e a assiduidade dos participantes, que eles demonstraram preocupação com os demais:

"Ouvi dizer que [Sócrates] sofreu infarto" (Raí em uma conversa com o mestrando antes das atividades coletivas, $14^{a}$ sessão de observação). "Eu visitei [Sócrates]. Ele está lá de repouso, mas está bem" (Falcão, $14^{\mathrm{a}}$ sessão de observação).

Foi percebido que os participantes se esforçam para manter o grupo.

"Eu não ia subir hoje. Só vim [à UBS] buscar medicamentos. Eles [apontando para alguns colegas do $\mathrm{GH}$ ] me viram lá embaixo. Eu vim aqui [auditório da UBS] puxado pelos colegas do grupo" (Rivaldo, $10^{\mathrm{a}}$ sessão de observação).

"Vi que estava vindo pouca gente no grupo. Então eu fiz esta camisa [personalizada] para o Grupo dos Homens, para andarmos com ela no bairro, divulgando este grupo para outros homens. [gesticulando e demonstrando que não concordava com a ausência dos colegas no grupo] Fiz esta camisa para chamar o povo, para encher isto aqui! (Sócrates, 24 $4^{\text {a }}$ sessão de observação)".

Essa iniciativa de fazer uma camisa para o GH revela a criação de identidade do grupo e autonomia dos usuários frente ao grupo, o protagonismo. 


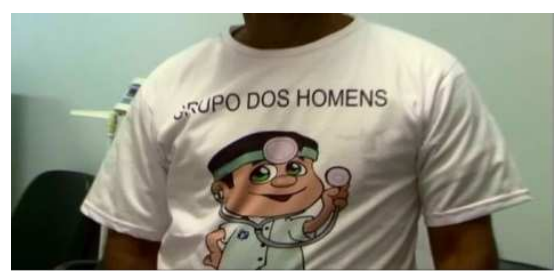

Figura 1 - Camisa personalizada do GH, iniciativa de Sócrates.

Nota-se que os participantes são multiplicadores do GH nas comunidades.

"Eu falo para meus amigos, que eu convido para virem no grupo, que podem vir, pois o trabalho dos atendentes é excelente. Eles atendem muito bem!" (Falcão, 14 a sessão de observação).

Por outro lado, os próprios participantes indicam que nem todos seus convidados comparecem ao $\mathrm{GH}$ :

"[...] Eu convido outras pessoas para participar do grupo [GH], mas elas não vêm [...]" (Zizinho, 14 a sessão de observação).

"[...] Tem gente que fala que 'aquilo lá' $[\mathrm{GH}]$ é só pra velho. Tem gente que diz que tem trabalho" (Falcão, 14 ${ }^{\mathrm{a}}$ sessão de observação).

Há o reconhecimento por parte dos profissionais desta dificuldade na adesão ao grupo, que se constitui obstáculo para a formação de vínculo dos usuários com o grupo e com a UBS como um todo:

"[Mozer] precisa muito de ajuda. Só vem quando a agente de saúde passa na casa dele. É tudo: álcool, drogas. Ele quer parar" (Acidália na reunião de equipe, $26^{a}$ sessão de observação).

Se por um lado há indícios de que os participantes do GH propagam esse espaço terapêutico nas comunidades, por outro, a equipe de saúde vinculada com o GH necessita refletir acerca da não adesão dos usuários que são convidados pelos participantes ou pelos profissionais. A partir dessa reflexão, a equipe poderá desvelar as (des)motivações acerca da frequência dos usuários no $\mathrm{GH}$, podendo propor estratégias efetivas para fomentar o vínculo de outros usuários com este grupo terapêutico, com intuito de aumentar a presença masculina na UBS e promover a saúde dos sujeitos.

Mesmo entre os participantes que frequentavam assiduamente o $\mathrm{GH}$ houve momentos de evasão. Alguns usuários deixaram de frequentar o GH (Adriano, Elano, Ganso, Neymar, Pato, Raí, Ramires, Romário, Vampeta e Vavá), não comparecendo mais até o encerramento da observação no campo de pesquisa. Portanto, o vínculo no GH é um processo incipiente a ser aperfeiçoado pela equipe de saúde.

Com a proximidade e o vínculo entre os usuários e profissionais, também emergiram conflitos no grupo. No decurso da pesquisa de campo, também foram presenciados casos de intolerância ao outro, o que indica a necessidade de desenvolver e fortalecer no GH um espaço que seja liberto de constrangimentos e com suspensão da 
atitude de julgamento moral. Durante uma apresentação feita pelas acadêmicas de farmácia, Vívian e Rebeca, sobre jogos olímpicos de inverno, Kaká perguntou:

“[Vívian], qual é o país que mais neva no mundo?" (Kaká, 20ª sessão de observação).

Imediatamente, Cafú ironizou:

"É na sua casa, lá no congelador! Tenho que sentar perto de um cara desses ainda..." (Cafú, 20ª sessão de observação).

O participante Kaká tem transtorno mental, mas não participa das atividades desenvolvidas no CAPS, e sim do GH, sendo que é assíduo. Ele consegue interagir com o grupo, apesar de algumas vezes suas falas serem desconexas e incompreensíveis. Destaca-se outro caso de estigma no grupo que envolveu o participante Kaká naquele dia. No momento em que ele entrou o auditório, o acadêmico de EF Bud se levantou a fim de ceder lugar para esse frequentador se acomodar. Todavia, o participante Sócrates, que estava sentado próximo a Bud, resmungou:

"Deixa ele para lá, pois ele fede pra caramba! Ninguém merece!" (Sócrates, 20ª sessão de observação).

Infere-se que Kaká é coibido de falar e até mesmo de frequentar o GH.

Outro participante, Jairzinho, também sofreu estigmatização. Após uma dinâmica de futebol de botão (que Jairzinho se saiu muito bem), Sócrates comentou em alta voz:

"Quem perder para [Jairzinho] vai ganhar de quem? [gargalhadas altas]" (Sócrates, 24 sessão de observação).

Jairzinho tem aproximadamente 60 anos de idade, anda com auxílio de uma muleta e também possui problemas mentais. A professora de EF Acidália contou um pouco a história dele na reunião de equipe:

"[Jairzinho] contou para mim e para [Simão] [psicólogo] por que ele
anda de muleta. Ele falou que jogava futebol profissionalmente,
quando era jovem. Mas, em certo momento, disse que se envolveu
com o tráfico. Foi quando foi baleado por rivais. Depois disso
Jairzinho abandonou a criminalidade. Hoje ele possui sequelas"
(professora de EF Acidália, $24^{\mathrm{a}}$ sessão de observação).

Essas posturas protagonistas de exclusão (descritas acima) desfavorecem relações de cooperação, ao passo que fortalecem relações de coação que são prejudiciais para o desenvolvimento de autonomia dos sujeitos. Portanto, essas posturas são nocivas à promoção da saúde que equivale, parcialmente, ao incremento de capacidade de enfrentamento, autonomia e participação democrática (SOUZA, 2012). 
Considerando a dimensão conceitual do vínculo assumida nesta pesquisa, constatam-se aspectos ambivalentes nas dimensões relacional e programática. Na primeira dimensão, observa-se que o $\mathrm{GH}$ fomenta o convívio social (assiduidade e esforço dos usuários para manter o grupo), companheirismo (cooperação e preocupação com os demais), sentimento de apoio (alguns usuários visitaram outros participantes enfermos), e proximidade entre equipe de saúde-usuário. Porém, os "dados" também mostram a evasão dos participantes do GH (alguns deixaram de frequentar o grupo e outros homens daqueles territórios não acolheram os convites dos colegas que participam do GH ou de profissionais de saúde), bem como conflitos entre eles (casos de estigmas), situações que dificultam o desenvolvimento e fortalecimento do vínculo.

No tocante a dimensão programática do vínculo, nota-se que a equipe de saúde busca desenvolver o vínculo por meio de dinâmicas de grupo, atividades lúdicas e esportivas, ampliando, assim, a concepção acerca de saúde. No entanto, à luz dessa dimensão, os "dados" evidenciam desafios aos vínculos, que incluem problemas organizacionais (agendamentos de consultas médicas para participantes do GH no horário do grupo), dificuldades no acesso dos usuários aos serviços da UBS (os profissionais de saúde conduziram os usuários para as recepcionistas; existência das filas tradicionais; horários dos serviços tipicamente comerciais), e rotatividade de profissionais no GH (problema agravado pela indefinição da política de pessoal do SUS).

\section{Protagonismo}

A despeito dos conflitos e limitações apontados na prática de grupo para a PS, nota-se que as vozes dos participantes também tiveram lugar no GH, o que propiciou aos participantes se apropriarem do $\mathrm{GH}$, se colocando em cena como protagonistas, opinando e participando das atividades desenvolvidas no grupo:

"Senti que as orientações de médicos no grupo estão ausentes" (Cafú, $12^{\mathrm{a}}$ sessão de observação).

Destaca-se que para fomentar o protagonismo do usuário, o profissional deve ser seu colaborador, deixando de ser autoridade absoluta do conhecimento. O usuário, por sua vez, deve ser considerado como plenamente ativo na construção de práticas de saúde - princípio de empoderamento, protagonismo (SOUZA, 2012). Foi percebido que no GH a equipe de saúde buscou fomentar a participação dos usuários dos serviços de saúde desde a etapa de planejamento das atividades, evidenciando, no discurso, que suas opiniões são relevantes:

"É muito importante que vocês participem desta etapa [planejamento], pois nós não desejamos que o grupo funcione em função dos profissionais, mas que vocês opinem, sugiram e participem, para que 
as atividades contemplem tuas demandas e necessidades específicas" (enfermeiro Bonifácio, $12^{\mathrm{a}}$ sessão de observação).

Observa-se que os participantes levaram propostas de atividades, deixando de ir ao grupo apenas para "receber", passando a "dar" também alguma contribuição.

\begin{abstract}
"Aposentei há nove anos. Lembro-me de quando trabalhava. Lá na empresa eu participava de grupo. Aqui poderia ter aquecimento com alongamento antes, pois no grupo da empresa que trabalhei tinha 'aquecimento' antes das reuniões e todos gostavam dessa atividade" (Raí, 14 sessão de observação). "Hoje eu vim 'seco' achando que teria aquele alongamento bom!” (Vavá, 19ª sessão de observação).
\end{abstract}

Outro exemplo de sugestão feita pelos participantes são as partidas de futebol em uma ONG local. Os participantes protagonizaram a organização das partidas ao sugerirem esta modalidade esportiva para o grupo, e ao providenciarem camisas para os times. Além disso, foi notado, durantes as partidas, que os frequentadores do GH também protagonizaram a cena como árbitros, constituindo "jogadores-árbitros", semelhantemente aos usuários do CAPS de Porto Alegre RS, participantes de oficinas de futebol pesquisadas por Abib et al. (2010). É o caso de Zizinho que pediu para a equipe do mestrando cobrar novamente um lateral, alegando que o time deu saída de bola "irregularmente", e de Raí que verbalizou, mesmo após a equipe adversária à sua ter saído com a bola, alegando que a posse de bola era do seu time (Diário de campo, $8^{\text {a }}$ sessão de observação). Foi constatado que no futebol os participantes assumiam um papel mais ativo no grupo, em comparação ao comportamento deles nas "palestras", ultrapassando o status de "pacientes" a cargo dos profissionais de saúde. Para eles, consoante Abib et al. (2010), deixar de ser meros coadjuvantes, mesmo que temporariamente, para serem sujeitos protagonistas do cuidado em saúde, funciona como um exercício de reinserção que transcende o ato de jogar bola.

No entanto, com o transcorrer do tempo, a partida de futebol passou a ser questionável entre os participantes do $\mathrm{GH}$.

"Gosto muito de futebol, porém meu joelho não deixa eu jogar" (Raí, $19^{a}$ sessão de observação).

"Por mim, pode acabar com o futebol. A médica falou comigo que não posso me machucar. Ela falou que não posso nem andar de chinelo, pois se eu machucar o pé vai ter que amputá-lo. Então, futebol pra mim acabou. Posso até ir para ficar sentado e assistindo, mas não posso jogar. Vai que dou azar de machucar?!" (Sócrates, 19ª sessão de observação).

"Não vou poder jogar bola, pois estou muito cansado por causa do meu serviço [esse participante trabalhava de porteiro durante a noite]" (Rivaldo, $18^{\mathrm{a}}$ sessão de observação). 
"Não vou jogar, pois trabalhei a noite inteira" (Vavá, 18ª sessão de observação).

No caso de Vavá, nem era aconselhável que ele jogasse com o grupo naquela manhã, pois sua taxa glicêmica registrada naquele dia foi igual a $370 \mathrm{mg} / \mathrm{dL}$. De um lado, os participantes do grupo demonstram imenso desejo de jogar futebol por influência do imaginário coletivo, por outro eles receiam se machucarem e piorarem as condições de saúde que já são muito precárias. Acrescenta-se a esse contexto o fato de os territórios adstritos à UBS Azul serem carentes de espaços públicos propícios para a prática de atividades físicas.

Não obstante as dificuldades foi observado que a equipe de saúde buscou estratégias de atividades inclusivas que possibilitassem o engajamento dos participantes do GH. A partir daí surgiram outras propostas feitas com os participantes. Em uma manhã em que duas acadêmicas de farmácia fizeram uma apresentação acerca de jogos olímpicos de inverno na Rússia, Cafú disse:

"Já que nem sempre todos estão dispostos a jogar futebol e já que aqui
não temos gelo igual lá [Rússia], nós poderíamos jogar bocha em vez
de futebol. Bocha é bom, pois todo mundo joga. Até quem tem dor no
pé. Joga homem e mulher, joga todo mundo!" (Cafú, $20^{\mathrm{a}}$ sessão de
observação).

E em um encontro o GH jogou bocha em uma praça localizada em um bairro próximo aos territórios adstritos à UBS Azul. Além de sugerir a modalidade para o grupo, Cafú providenciou o local para a realização do jogo junto ao Presidente da cancha de bocha na semana anterior. Os participantes demonstraram familiaridade com o jogo, atuando como instrutores para o enfermeiro Bonifácio e os três acadêmicos que estiveram naquele encontro, explicando questões de pontuação, principais regras e posições para fazer as jogadas (Diário de campo, 22ª sessão de observação).

Nessa direção, o GH como um GPS deve se constituir em um espaço cooperativo onde os participantes têm a oportunidade de valorizar os conteúdos disponíveis na comunidade (SANTOS et al., 2006), contribuindo para a integração social ao fomentar acesso a espaços de socialização como a praça da bocha. Essas vivências também oportunizam os usuários se organizarem e reivindicarem junto ao Poder Municipal estruturas para a prática de atividades físicas e de lazer, como uma cancha de bocha, calçadão para caminhadas e quadras esportivas, semelhantemente ao grupo de caminhada da UBS Jardim Carla, Santo André/SP, que se reuniu com a comunidade para reivindicar, com sucesso, a construção de uma pista de caminhada (WARSCHAUER; D’URSO, 2009), o que não ocorreu no GH até o último dia de observação desta pesquisa.

Outra modalidade que teve caráter inclusivo com potencial para incentivar o protagonismo dos sujeitos foi o futebol de botão, jogo praticado na $24^{\text {a }}$ sessão de 
observação e sugerido pelos acadêmicos de EF. Nessa modalidade, de modo similar ao bocha, para o jogo ter acontecido foi necessário cada participante colaborar com o outro. A lógica, então, é jogar "com" e não "contra" o outro. Essas atividades propiciam que os sujeitos desenvolvam uma opinião positiva de si mesmos e reconheçam a importância do outro, uma concepção que frisa a importância de cada sujeito e de sua relevância para o convívio em coletividade.

Não obstante as estratégias de sociabilidade e inclusão abordadas anteriormente, também foram constatadas situações que evidenciaram inércia por parte dos participantes no GH. Em uma manhã, os profissionais e acadêmicos mostraram e disponibilizaram os materiais (atadura gessada, tesouras e recipientes com água) necessários para confecção de máscaras, e explicaram como se fazia uma máscara com atadura gessada e incentivaram os participantes do $\mathrm{GH}$ a fazerem um no outro uma máscara. Contudo, com unanimidade os 11 frequentadores do $\mathrm{GH}$ presentes ficaram estáticos, sem iniciativa. Após diálogos, os participantes preferiram que os profissionais e acadêmicos fizessem as máscaras neles, alegando que nunca fizeram aquela atividade (Diário de campo, 16 ${ }^{\mathrm{a}}$ sessão de observação).

Embora haja interessantes momentos de protagonismo dos participantes no $\mathrm{GH}$, nota-se neles certa dependência dos profissionais, concepção compartilhada por membros da equipe de saúde:

"Ainda sinto que o grupo é muito dependente dos profissionais. Se os profissionais não tomarem a iniciativa, os participantes têm a tendência de também ficarem parados. É necessário dar mais autonomia ao grupo" (acadêmica Simone na reunião de equipe, $15^{\mathrm{a}}$ sessão de observação).

"Penso trabalhar a autonomia dos participantes do grupo, de modo que um dia eles possam conduzir encontros, auxiliados por nós [profissionais e acadêmicos]" (enfermeiro Bonifácio na reunião de equipe, $15^{\mathrm{a}}$ sessão de observação).

Desenvolver o protagonismo no grupo se mostra essencial, pois alguns usuários não possuem mais motivação e evidenciam incapacidade para cuidar de si de forma autônoma.

"O mau cheiro de [Kaká] é por falta de banho mesmo. O fedor não é de bebida, pois ele não é de beber. Ele já revelou para mim que gosta de pó." (Acidália na reunião de equipe, $15^{a}$ sessão de observação).

"Gente, hoje seu [Rivelino] estava fedendo, fedendo, fedendo! Estava insuportável! [elevando as mãos na testa com expressão de tristeza] Será que ele não sente esse mau cheiro, não? Alguém precisa dar um toque nele!" (Acidália na reunião de equipe, $16^{\mathrm{a}}$ sessão de observação).

"Gente, [Leônidas] mora sozinho num buraco. Ele não tem ninguém por ele. Perguntei se ele tomou banho, quando fui ver o curativo no 
seu pé agora pouco! [...]" (Acidália na reunião de equipe, 24a sessão de observação).

Partindo da dimensão conceitual do protagonismo, que situa os usuários dos serviços como corresponsáveis pelo cuidado em saúde, também aparecem questões ambivalentes nas dimensões relacional e programática do protagonismo. Constata-se, em relação à dimensão relacional, que no contexto das práticas desenvolvidas no GH os participantes evidenciaram mudança de papel e seus efeitos no grupo, deixando de irem ao grupo apenas para receberem, mas para contribuírem também. Os "dados" também mostraram um engajamento significativo dos participantes no planejamento das atividades desenvolvidas no grupo. No entanto, nessa dimensão também aparece atitude de inércia dos participantes do GH no fazer, situação que repercute na vida de alguns que demonstraram inépcia para cuidar de si. Essa indolência dos participantes coexistiu mesmo em um contexto em que, na dimensão programática, os profissionais buscaram fomentar a participação deles desde a fase do planejamento das atividades, bem como propuseram atividades inclusivas buscando atender e ouvir a todos. Então, o problema aqui paira na dimensão relacional, onde os sujeitos necessitam fortalecer a postura participativa e democrática que, diante dos problemas abordados na categoria analítica "desenvolvimento de vínculo" (estigmatizações no grupo), acaba ficando mais difícil. À luz da dimensão programática do protagonismo, os profissionais demonstraram interesse em estimular a participação dos usuários nas atividades e no cuidado em saúde, porém, no "como fazer" os usuários assumirem o papel de protagonistas, os profissionais acabam não tendo muito claro esse processo quando demonstram casos de "censura" no grupo, tal como abordado na categoria "espaço comunicacional", o que influencia negativamente na postura dos usuários no GH. Além disso, sem solucionar os problemas das dimensões relacional e programática da categoria "desenvolvimento de vínculo", fica complicado para a equipe de saúde promover efetivamente o protagonismo dos usuários no grupo e na vida, uma vez que o vínculo é um elemento fundamental quando falamos da adesão às práticas de saúde. E sem adesão, não há corresponsabilidade, não há vínculo e participação dos usuários dos serviços na produção de práticas de saúde.

\section{Considerações Finais}

A análise do diário de campo permitiu a identificação de três principais categorias referentes às práticas desenvolvidas no GH, à luz da Clínica Ampliada: estímulo e constituição de um espaço comunicacional, vínculo e protagonismo. Esses eixos analíticos estão imbricados com as tecnologias "leves" no trabalho em saúde, tecnologias favorecidas pelas oficinas terapêuticas e que envolvem o acolhimento, a escuta qualificada, "atitudes psicoterapêuticas", a dimensão relacional e de encontro no cuidado em saúde, algumas das facetas da Clínica Ampliada. Apesar de o GH ser uma prática singular e local, destaca-se que esses recursos normalmente estão disponíveis 
nas UBS, o que os tornam exequíveis em outras unidades de saúde em conformidade com as singularidades de cada território sanitário.

\section{REFERÊNCIAS}

ABIB, Leonardo Trápaga et al. Práticas corporais em cena na saúde mental: potencialidades de uma oficina de futebol em um Centro de Atenção Psicossocial de Porto Alegre. Pensar a Prática, Goiânia, v. 13, n. 2, p. 1-15, 2010.

BRASIL. Ministério da Saúde. Gestão participativa e cogestão. Brasília, 2009. (Cadernos HumanizaSUS; v. 2)

BRASIL.Ministério da Saúde. Política Nacional de Atenção Integral à Saúde do Homem: princípios e diretrizes. Brasília DF, 2008.

CÂMARA, Rosana Hoffman. Análise de conteúdo: da teoria à prática em pesquisas sociais aplicadas às organizações. Revista Interinstitucional de Psicologia, Juiz de Fora, v. 6, n. 2, p. 179-191, 2013.

CAMPOS, Claudinei José Gomes. Método de análise de conteúdo: ferramenta para a análise de dados qualitativos no campo da saúde. Revista Brasileira de Enfermagem, Brasília, v. 57, n. 5, p. 611-614, 2004.

CAMPOS, Gastão Wagner de Sousa. Entrevistas curtas com sanitaristas sobre o SUS. Revista do Instituto Humanistas Unisinos, 2008. Disponível em: < http://www.ihuonline.unisinos.br/media/pdf/IHUOnlineEdicao260.pdf >. Acesso em: 02 jun. 2016.

CAMPOS, Gastão Wagner de Sousa. Mais médicos e a construção de uma política de pessoal para a Atenção Básica no Sistema Único de Saúde (SUS). Interface comunicação, saúde, educação, Botucatu, 2015. Disponível em: < http://www.scielosp.org/pdf/icse/2015nahead/1807-5762-icse-1807 576220150286.pdf >. Acesso em: 02 jun. 2016.

CAVALCANTE, Ricardo Bezerra; CALIXTO, Pedro; PINHEIRO, Marta Macedo Kerr. Análise de Conteúdo: considerações gerais, relações com a pergunta de pesquisa, possibilidades e limitações do método. Informação \& Sociedade: estudos, João Pessoa, v. 24, n. 1, p. 13-18, 2014.

FERREIRA NETO, João Leite; KIND, Luciana. Promoção da saúde: práticas grupais na estratégia saúde da família. São Paulo: Hucitec, 2011. 182p. 
FURLAN, Paula Giovana; CAMPOS, Gastão Wagner de Sousa. Os grupos na Atenção Básica à Saúde. In: BRASIL. Ministério da Saúde. Secretaria de Atenção à Saúde. Política Nacional de Humanização. Cadernos HumanizaSUS: v. 2. Brasília, 2010. p. 105- 116.

GADELHA, Paulo. Entrevistas curtas com sanitaristas sobre o SUS. Revista do Instituto Humanistas Unisinos, n. 260, p. 16-19, 2008. Disponível em:

<http://www.ihuonline.unisinos.br/media/pdf/IHUOnlineEdicao260.pdf>. Acesso em: 02 jun. 2016.

HECKERT, Ana Lucia C. Escuta como cuidado: o que se passa nos processos de formação e de escuta? In: PINHEIRO, Roseny; MATTOS, Ruben Araújo de. (Org.). Razões públicas para a integralidade em saúde: o cuidado como valor. Rio de Janeiro: ABRASCO/CEPESC, 2007. v. 1. p. 199-212, 2007.

HENNINGTON, Élida Azevedo. Acolhimento como prática interdisciplinar num programa de extensão universitária. Cadernos de Saúde Pública, Rio de Janeiro, v. 21, n. 1, p. 256-265, 2005.

IGLESIAS, Alexandra; DALBELLO-ARAUJO, Maristela. As concepções de promoção da saúde e suas Implicações. Caderno Saúde Coletiva, Rio de Janeiro, v. 19, n. 3, p. 291-298, 2011.

SANTOS, Luciane de Medeiros dos Santos et al. Grupos de promoção à saúde no desenvolvimento da autonomia, condições de vida e saúde. Revista de Saúde Pública, São Paulo, v. 40, n. 2, p. 346-352, 2006.

SEPARAVICH, Marco Antonio; CANESQUI, Ana Maria. Saúde do homem e masculinidades na Política Nacional de Atenção Integral à Saúde do Homem: uma revisão bibliográfica. Saúde e Sociedade, São Paulo, v. 22, n. 2, p. 415-428, 2013.

SOUZA, Luiz Gustavo Silva. Profissionais de saúde da família e representações sociais do alcoolismo. 2012. Dissertação (Mestrado em especialização em Psicologia) Universidade Federal do Espírito Santo, Espírito Santo, 2012.

SOUZA, Luiz Gustavo Silva et al. Intervenções psicossociais para promoção da saúde do homem em unidade de saúde da família. Psicologia: ciência e profissão, Brasília, v. 35, n. 3, p. 932-945, 2015.

TESSER, Charles Dalcanale; POLI NETO, Paulo; CAMPOS, Gastão Wagner de Sousa. Acolhimento e (des)medicalização social: um desafio para as equipes de saúde da família. Ciência e Saúde Coletiva, Rio de Janeiro, v. 15, supl. 3, p. 3615-3624, 2010. 
VASCONCELOS, Kathleen Elane Leal; SCHMALLER, Valdilene Pereira Viana. (Nova) promoção da saúde: configurações no debate do serviço social. Revista Emancipação, Ponta Grossa, v. 14, n. 1, p. 129-146, 2014.

WARSCHAUER, Marcos; D'URSO, Lourdes. Ambiência e formação de grupo em programas de caminhada. Saúde e Sociedade, São Paulo, v. 18, n. 2, p. 104-107, 2009. 